\title{
Enzyme Inhibition Microassays on Blu-Ray Disks for Drug Discovery
}

\author{
Gabriel Sancho-Fornes, ${ }^{\dagger}$ Ernest Peris, ${ }^{\dagger}$ David Giménez-Romero, ${ }^{\ddagger}$ Sergi Morais, ${ }^{\dagger}$,

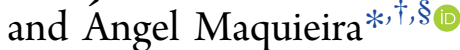

\begin{abstract}
${ }^{\dagger}$ Instituto Interuniversitario de Investigación de Reconocimiento Molecular y Desarrollo Tecnológico (IDM), Universitat Politècnica de València, Universitat de València, Camino de Vera s/n, 46022 Valencia, Spain

${ }^{\ddagger}$ Departamento de Química-Física, Facultad de Química, Universitat de València, Avda. Dr. Moliner 50, 46100 Burjassot, Spain

${ }^{\S}$ Departamento de Química, Universitat Politècnica de València, Camino de Vera s/n, 46022 Valencia, Spain
\end{abstract}

\section{Supporting Information}

\begin{abstract}
An enzyme inhibition-based assay for drug discovery developed by microarraing on Blu-ray disks is presented. As a proof-of-concept, the system screens a selected molecule library of potential chemical inhibitors against the glycoenzyme peroxidase, identifying the promising lead compounds with high selectivity using standard Blu-ray disks and drives. In order to face the first drug discovery stages, we establish the bases for a high-throughput screening assay and a methodology based on hypersurfaces suitable to manage a high number of data as well.
\end{abstract}

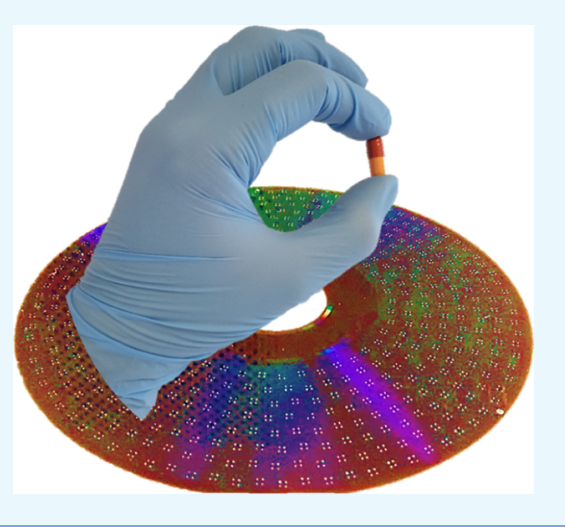

\section{INTRODUCTION}

High-throughput screening (HTS) techniques for drug discovery identify hits during primary single-point screening, followed by lead generation using dose-response analyses. ${ }^{1-3}$ These techniques transformed drug discovery, surpassing traditional screening methodologies and allowing researchers to approach potential candidates in a rational manner., Although target compounds are able to display complex concentration-dependent relationships and structure-activity ratios, usually a single measurement at a single concentration is taken per compound in the chemical library during a primary drug screening. ${ }^{6}$ This working strategy results in low performances in terms of characterizing compounds and poor quality data.

HTS assays based on enzyme inhibition have been widely employed for drug discovery. ${ }^{7-10}$ Most of the enzymes are proteins that take part in a wide variety of processes inside living organisms, such as signal transduction and cell regulation. In this sense, several human diseases are associated with enzyme regulation. ${ }^{11,12}$ For example, Alzheimer's disease is treated by the inhibition of acetylcholinesterase, ${ }^{13}$ diabetes mellitus through the inhibition of $\alpha$-glucosidase, ${ }^{14}$ or cardiovascular diseases where the treatment is based on the regulation of thrombin. ${ }^{15}$ Discovering new enzyme inhibitors that treat diseases or improve those that exist in the actuality are important for the human health point of view. ${ }^{16-21}$

We present a methodology that uses Blu-ray-based microarray technology (disks as assay platform and a disk-player as detector) to perform assays for drug screening of inhibitors against horseradish peroxidase (HRP) as a member of the glycoenzymes superfamily. ${ }^{22}$ We establish the basis for the development of high-throughput screening assay using compact disk technology and develop a novel strategy based on kinetic and thermodynamic parameters for drug discovery, identifying hits during primary screening stages.

\section{RESULTS AND DISCUSSION}

Blu-ray disks have a reliable surface for creating and handling high-density microarrays. ${ }^{23,24}$ In this article, we perform a screening assay of inhibitors against HRP as a proof-of-concept of the potential use of Blu-ray technology for drug screening. For that, HRP was anchored in an oriented manner, utilizing bioaffinity-based immobilization on Concanavalin A (ConA) microarrays. The strong affinity of lectins (ConA) for glycoenzymes (HRP) was employed for this purpose as this immobilization procedure exhibited high catalytic activity and improved stability against denaturation (see Figure S1). ${ }^{25}$

First, the relationship between the signals generated by the activated ConA/HRP system and the ConA concentration was established. As is shown in Figure S2B, the curve displayed a typical pattern with no distinguishable signal at the low ConA concentration values (i.e., not enough protein to bind HRP), followed by an increase between 10 and $40 \mathrm{mg} / \mathrm{L}$ and a final plateau at higher lectin values. From these data, $40 \mathrm{mg} / \mathrm{L}$ was chosen to be the optimum ConA concentration value after

Received: December 17, 2018

Accepted: March 12, 2019

Published: March 20, 2019 

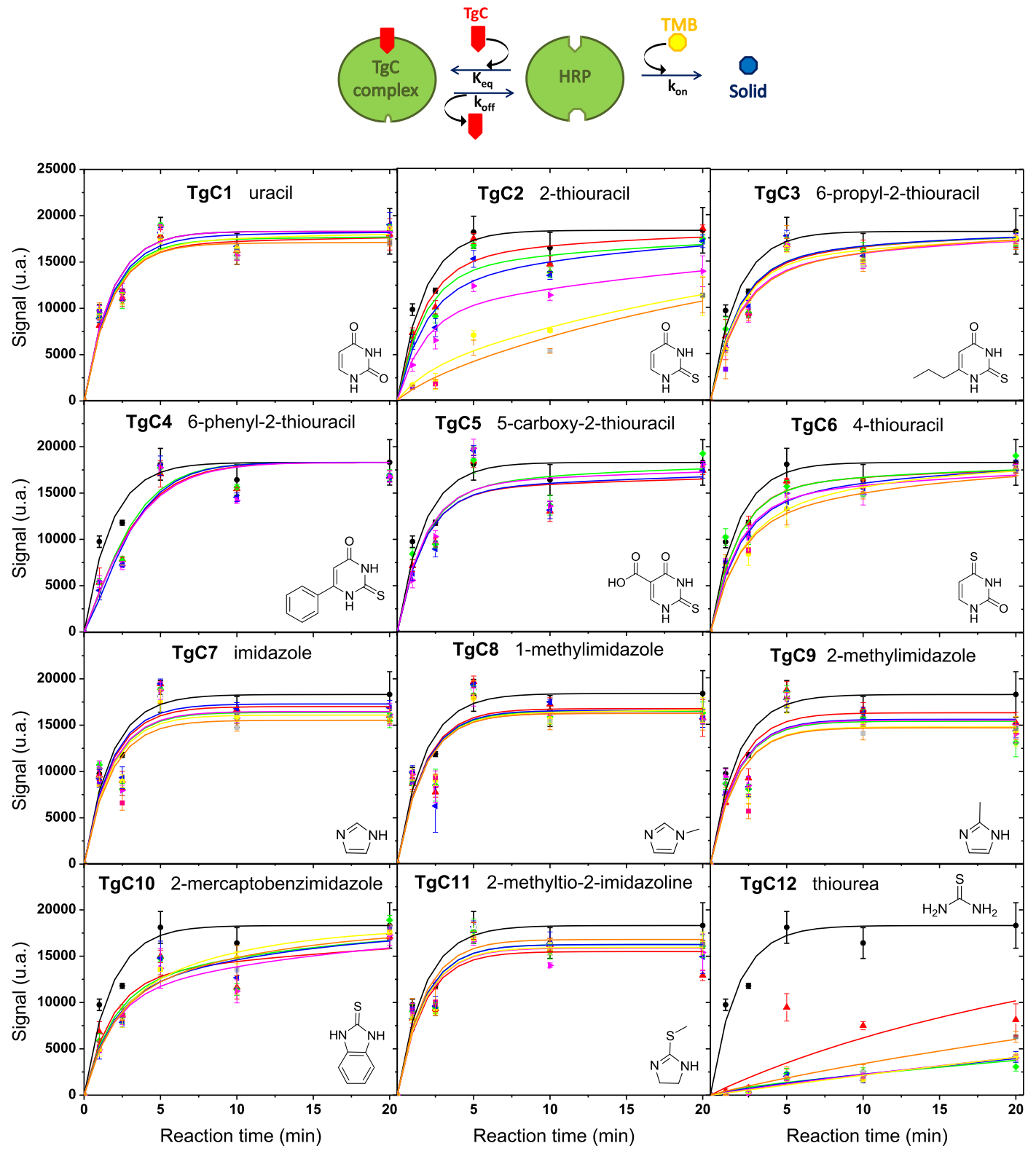

Figure 1. Schematic theoretical model representing the process of HRP-TgC complex formation. The plots show the signal registered from bioimmobilized HRP reaction toward TMB substrate in the presence of the target compounds at different concentrations (blank [black circle], 0.64 $\mathrm{mM}$ [red triangle], $1.25 \mathrm{mM}$ [green diamond], $2.5 \mathrm{mM}$ [blue left pointing triangle], $5 \mathrm{mM}$ [pink right pointing triangle], $10 \mathrm{mM}$ [yellow hexagon], and $20 \mathrm{mM}$ [orange rectangle]). Each result is the mean \pm sd of 6 values and lines correspond to data fittings to eq 1.

considering that slight experimental errors in ConA steps did not affect the signal. The results obtained with the nonactivated ConA shows that the nonspecific interaction between ConA and HRP was not observed. This was probably because $\mathrm{Ca}^{2+}$ and $\mathrm{Mn}^{2+}$ were absent. Indeed, these cations are essential to allow lectin to fold in a tertiary structure that is complementary to glycoprotein sugar residues. ${ }^{26}$

In order to select the suitable concentration of HRP to perform the assays, the effect on the ConA/HRP signal was recorded after developing with 3,3',5,5'-tetramethylbenzidine (TMB). The data are shown in Figure S2C. A linear correlation was obtained within the concentration range between 5 and $40,20 \mathrm{mg} / \mathrm{L}$ being suitable for the signal intensity requirements of the $\mathrm{BD}$-player.

HRP activity was monitored from 1 to $20 \mathrm{~min}$ at room temperature by time-course curves using a simple kinetic model in an enzyme-catalyzed direct reaction (see Figure S2). These assays were performed in the absence of TgCs as reference for full enzymatic activity (blank). The HRP activity is accurately obtained by 36 data points (each array containing 6 spots and 6 reaction times were analyzed), measuring the conversion of the TMB substrate into an insoluble colored product. The measurements were taken through reading the $\mathrm{BD}$ by the disk drive, as described elsewhere. ${ }^{27}$ The obtained data were exponentially fitted to $S=S_{\mathrm{Max}}\left(1-\mathrm{e}^{\left(-k_{\mathrm{on}} t\right)}\right)$, which provided a maximum signal value $S_{\mathrm{Max}}=18300 \pm 1400$ (a.u.) and a rate constant value of $k_{\text {on }}=0.57 \pm 0.14 \mathrm{~min}^{-1}\left(R^{2}=\right.$ $0.963)$. These two parameters were required to accomplish subsequent data fittings to eq 1 in order to obtain the inhibition parameters with maximum precision.

In order to demonstrate the concept, 12 target compounds (TgCs) were screened for HRP activity inhibition (see the 
screening criteria in Supporting Information). The large amount of data obtained from each drug target (6 concentrations per drug, 6 different reaction times of TMB, and 6 replicates) involved an accurate analysis of the timecourse curves to collect as much information as possible. For that, a data fitting using a basic competitive inhibition-based model was performed and evaluated by the Bayesian information criterion (see Table S1). In the competitive inhibition assay format, the inhibitor vies with the substrate for the free enzyme, but each precludes the binding of the other. The scheme of the model is depicted in Figure 1. This implies that both the inhibitor and substrate bind to the active site, which is generally true. Thus, the corresponding mathematical expression to describe this reaction mechanism is shown in eq 1.

$$
\begin{aligned}
S= & S_{\mathrm{Max}}+\left[\mathrm { e } ^ { - ( k _ { \mathrm { on } } + k _ { \text { off } } ) t } \left(-S_{\mathrm{Max}} \cdot \mathrm{e}^{\left(k_{\mathrm{on}} t\right)} \cdot C K_{\mathrm{eq}} \cdot k_{\text {on }}+S_{\mathrm{Max}}\right.\right. \\
& \left.\left.\mathrm{e}^{\left(k_{\mathrm{off}} t\right)}\left(-k_{\mathrm{on}}+k_{\text {off }}+C K_{\mathrm{eq}} k_{\text {off }}\right)\right)\right] /\left[\left(1+C K_{\mathrm{eq}}\right) \cdot\left(k_{\text {on }}-k_{\text {off }}\right)\right]
\end{aligned}
$$

where $S$ denotes the signal obtained at a certain time $(t)$ and $\mathrm{TgC}$ concentration $(C) . S_{\mathrm{Max}}$ is the signal at an infinite time, $K_{\text {eq }}$ is the constant of equilibrium for the $\mathrm{TgC}$ complex and the free enzyme, $k_{\text {off }}$ is the dissociation rate constant for the TgC complex, and $k_{\text {on }}$ is the rate constant for the formation of the enzymatic product.

The inhibiting capacities of TgCs might be related to their concentration and affinity to the native enzyme, which can be quantified with the parameter $C K_{\text {eq }}$ that equals the inhibitor concentration multiplied by the equilibrium constant. This parameter discriminates potential inhibitors $\left(C K_{\mathrm{eq}}>0\right.$, i.e., favorable $\mathrm{HRP}-\mathrm{TgC}$ complex formation) from noninhibitors $\left(C K_{\text {eq }} \approx 0\right.$, i.e., low HRP-TgC complex formation). Note how low $C K_{\text {eq }}$ values indicate high free enzyme population on the microarray surface, which result in high optical density precipitates (signal). The $k_{\text {off }}$ parameter is a guideline of $\mathrm{HRP}-\mathrm{TgC}$ binding strength, and the possible release of TgC from the enzymatic active site depends entirely on the nature of the compound, and could be used to discern between reversible $\left(k_{\text {off }}>0\right)$ and irreversible $\left(k_{\text {off }} \approx 0\right)$ inhibitors. Hence, 216 data per drug target were analyzed to characterize the enzyme inhibitor capacity of each compound in a total time of $40 \mathrm{~min}$.

The experimental inhibitor capacity and the accuracy of the mathematical approach in reproducing the screening data are shown in the plots of Figure 1. These inhibition parameters (Table S2) were analyzed in an attempt to decide which of the initial TgC selection hypotheses displayed real importance.

After evaluating the $C K_{\text {eq }}$ values for compounds $\mathrm{TgC1}$, TgC5, TgC7, TgC8, TgC9, and TgC11, it was ruled out that the HRP-TgC complex was not extensively formed and the target substance would not be considered an inhibitor. Thus, only $\mathrm{TgC} 2, \mathrm{TgC} 3, \mathrm{TgC} 4, \mathrm{TgC} 6, \mathrm{TgC} 10$, and $\mathrm{TgC} 12$ showed inhibition activity.

Regarding the presence of heteroatoms, the existence of a ketonic oxygen at position 2 on the main aromatic ring did not retrieve any inhibitory behavior $(\mathrm{TgCl})$, nor when a thioureide group $(\mathrm{TgC} 11)$ was tested. Thus, when comparing the inhibitory capacity of $\mathrm{TgCl}, 7-9$ and 11 to the other targeted compounds, position 2 should be occupied by a sulphur atom in the thione form. The behaviors of $\mathrm{TgCl}$ and $\mathrm{TgC} 11$ were ascribed to the distinct electronegative charge distribution for the keto-enol equilibrium in the former, and the impossibility to achieve the corresponding thione-thiol equilibrium in the latter. Although TgC5 had a thioureide group at position 2, no HRP inhibition was recorded. This could be related to the position of the ring substituent, which might not only affect the optimal size distribution of the target substance, but also the inefficient charge interactions of the deprotonated carboxylic group $\left(\mathrm{pK}_{\mathrm{a}} 4.7\right.$ vs inhibition step $\mathrm{pH}$ 7.5 ) with the amino acid residues located in the enzyme cavity. Besides, the existence of secondary amines at positions 1 and 3 on the aromatic ring was not the only requisite for binding $\mathrm{TgC7}$ to the enzyme active site, nor was there a clear effect of the presence of a methyl residue at position 2 or 3 , as occurred with TgC8 and TgC9. The other TgC2-4, TgC6, and $\mathrm{TgC} 10$ compounds had a clearer inhibition effect on HRP activity because of the presence of the preferred thione group surrounded by secondary amines (i.e., the thioureide functional group).

TgC6 was tested to ensure that the relative thioureide group position on the aromatic ring was determinant for the interaction with the enzyme. When compared to $\mathrm{TgC} 2$, an 8 -fold lower inhibitory character was observed for the equivalent experiments at the $10 \mathrm{mM}$ level. Consequently, the position of the thione atoms was concluded to be key.

The presence of propyl-( $\mathrm{TgC} 3)$ and phenyl- $(\mathrm{TgC} 4)$ hydrocarbonated substituents on the thiouracil ring was also tested. Results showed that the existence of such pendant moieties could cause steric hindrance during the interaction of these substances with the enzyme, which would hinder their access to the heme cavity and, thus, their inhibitory power compared to $\mathrm{TgC}$. The interaction seemed, however, more favorable in $\mathrm{TgC} 4$ than in $\mathrm{TgC} 3$, which was possibly because of the affinity of the phenyl substituent for the hydrophobic environment inside the enzyme cavity.

HRP activity was also analyzed by considering the rigidity of the target structure. Here, $\mathrm{TgC10}$ was a less powerful inhibitor compared to $\mathrm{TgC} 4$ (3-fold at $0.64 \mathrm{mM}$ ), which was possibly because of the restricted spatial conformation of the phenyl substituent (fused to the principal ring in $\mathrm{TgC10}$, but possessed higher freedom degrees in $\mathrm{TgC} 4$ ). Finally, the substantial inhibitory power of the $\mathrm{TgC12}$ compound was explained after assuming that it possessed the predicted thioureide functional group to bind the HRP heme site with no steric hindrance. This conclusion was confirmed as is shown in Figure 2, which depicts how the thiourea compound is a powerful enzyme inhibitor, while urea is not.

In view of these data, it is possible to state that the exposed screening process exploits the structure-activity ratios to identify promising lead compounds. To this end, each inhibitor candidate was defined by a three-dimensional vector, ([TgC], $\left.[\mathrm{TgC}] \times K_{\text {eq }}, k_{\text {off }}\right)$. These vectors considered the concentration ([TgC] coordinate), inhibitory strength $\left([\mathrm{TgC}] \times K_{\mathrm{eq}}\right.$ coordinate), and reversibility ( $k_{\text {off }}$ coordinate) behaviors of any potential lead compound. Hence, this vector allows active compounds to be identified $\left(K_{\mathrm{eq}}\right.$ and $\left.k_{\text {off }}\right)$ and quantified $([\mathrm{TgC}])$ in only one assay. As mentioned above, this novel vector greatly reduced the occurrence of outlaying data points, and generated much more helpful data than those produced by currently available assays. The three-dimensional vector provided information on the structure and inhibitory mechanism of the unknown $\mathrm{TgC}$.

\section{MULTIDRUG SCREENING RESULTS}

In order to exploit the working capacity of Blu-ray-based microarray technology and the versatility of the three- 


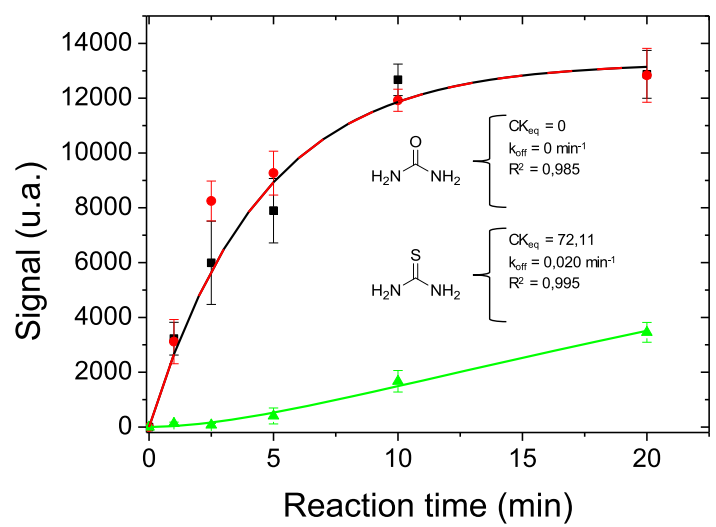

Figure 2. Signal registered from bioimmobilized HRP reaction toward the TMB substrate in the absence [black square] and presence of 5 $\mathrm{mM}$ of urea [red circle] or $5 \mathrm{mM}$ of thiourea [green triangle]. The values are the mean of six values. Lines correspond to data fittings to eq 1 .

dimensional vector approach, a multiple high-density microarray format was developed. As shown in Figure S3, 367 arrays of different $\mathrm{TgC}$ solutions with four replicates each were performed on a BD, corresponding to a total of 1468 assays (see HTS Experimental Section in Supporting Information). The $\mathrm{TgC}$ solutions were previously dropped on a polycarbonate (PC) plate with a pattern that matches with the arrays of HRP immobilized on the BD surface (Figure $3 \mathrm{~A}$ ). This

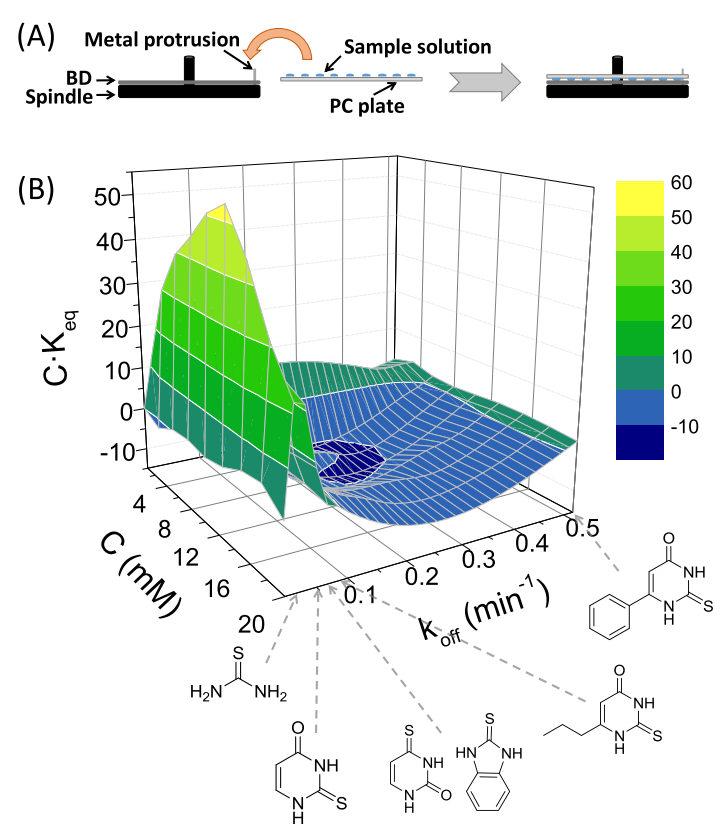

Figure 3. (A) Scheme depicts the protocol to create a drop pattern of 367 different $\mathrm{TgC}$ solutions on the Blu-ray surface. (B) Hypersurface generated from the panel of TgCs analyzed as bioimmobilized HRP inhibitors. $k_{\text {off }}\left(\mathrm{min}^{-1}\right),[\mathrm{TgC}](\mathrm{mM})$ and $C K_{\mathrm{eq}}$ are plotted on the $X$, $Y$, and $Z$ axis, respectively.

suggests that, whenever required and depending on the chemical system, a Blu-ray disk surface can be employed as a high-density microarraying platform by covering it with over thousands drops by simply reducing the sample volume, being able to address multiple drug screenings and hit to lead stages.

All these data allow the characterization of multiple TgCs by means of the three-dimensional vector. This information must be processed properly in order to avoid tedious interpretation process. For that, the three-dimension characterization vectors are organized and hierarchized to display the information to the analyst. To do this, the three-dimensional vectors were visualized by means of a $3 \mathrm{D}$ graphic hypersurface (Figure 3B). Note that the $\mathrm{nD}$ graphic hypersurfaces were traced if the $\mathrm{n}$ dimensional vectors were defined what might increase the sensitivity and selectivity of the screening assay. It is also worth mentioning that $\mathrm{n}$-dimensional vectors might be achieved by measuring more parameters. This treatment allowed the immediate visual grouping of the targeted compounds through the existence of peaks and valleys that enabled the easy analysis of structural-activity ratios. Hypersurfaces locate the hotspot areas of any biochemical system and relate them to the ndimensional parameters under study ${ }^{28}$ to select the most promising lead compound.

As a proof-of-concept, we introduce the hypersurface term using the parameters obtained in the enzyme inhibition study. In a real situation, we should simply perform the same assay, but the selected $\mathrm{TgCs}$ could be many more, such as the hypersurface concept supports. Accordingly, Figure 3B shows the hypersurface generated from the panel of TgCs analyzed as bioimmobilized HRP inhibitors. This figure shows a clear peak that was differentiated on the hypersurface located within the $C K_{\text {eq }}$ and $k_{\text {off }}$ 0.24-47.68 and $0-0.01 \mathrm{~min}^{-1}$ ranges, respectively. For the higher $k_{\text {off }}$ values, a deeper valley covered the area to $0.520 \mathrm{~min}^{-1}$, when a new land tended to rise. Overall, two hotspot areas were detected to be of great interest for further research. However, the promising lead compound was located very easily on these hypersurfaces by tracking the maxima because this peak corresponded to the most potent inhibitors (high $K_{\mathrm{eq}}$ values). In this demonstration model, the lead compound that predicted the drawn hypersurface was thiourea as previously confirmed. It is possible to say that this drug screening assay might facilitate the interpretation process, as well as its implementation on a robotic platform for quantitative high-throughput screening in microarray format.

\section{CONCLUSIONS}

We have developed an enzyme inhibition assay to test the pharmacological potential of several compounds. The results presented herein demonstrate that Blu-ray disk microarray technology allows inhibitor compounds to be discriminated, identified, characterized, and quantified in a single assay. Large amounts of information have been obtained from small sample volumes (more than 200 data points per drug), which have allowed to obtain the parameters that evaluate the binding affinity of the drug and the enzyme. The proposed methodology exploits the information on inhibitory strength and reversibility behaviors of any $\mathrm{TgC}$ to identify promising lead compounds.

This approach works well mainly for enzymes that directly convert a substrate into an insoluble reaction product, but it is possible to use indirect developers such as nanoparticles to open the field of applications.

Our development based on Blu-ray technology is a realistic option to optimize physicochemical and biopharmaceutical properties in drug screening through precise measurement of structure-activity ratios with minimal quantities of reagents and time. Besides, its low cost $(\approx 0.5 \$ /$ disk $)$, widespread use, and scan speed make the proposed methodology a powerful versatile tool for conducting drug discovery processes, which 
influences both the work's strategic direction and drives the design of compounds for further synthesis.

\section{EXPERIMENTAL SECTION}

Reagents. All the buffers (printing carbonate buffer (CB): $0.015 \mathrm{M} \mathrm{Na}_{2} \mathrm{CO}_{3}$ and $0.035 \mathrm{M} \mathrm{NaHCO}_{3}, \mathrm{pH}$ 9.6; phosphate saline buffer (10 mM PBS buffer, $\mathrm{pH} 7.5$ ), prepared from 10fold concentrated PBS: $80 \mathrm{mM}$ sodium phosphate dibasic, 15 $\mathrm{mM}$ potassium phosphate monobasic, $1.369 \mathrm{M}$ sodium chloride and $27 \mathrm{mM}$ potassium chloride, $\mathrm{pH}$ 7.5; PBS-T: 10 $\mathrm{mM}$ PBS containing $0.05 \%(\mathrm{v} / \mathrm{v})$ Tween 20 (PBS-T), $\mathrm{pH} 7.5$; citrate buffer (CitB): $25 \mathrm{mM}$ monohydrate citric acid and 62 $\mathrm{mM} \mathrm{NaH}{ }_{2} \mathrm{PO}_{4}, \mathrm{pH}$ 5.5; ConA activation buffer (CAB): 100 $\mathrm{mM}$ Trizma base, $80 \mathrm{mM}$ glycine, $3 \mathrm{mM} \mathrm{CaCl}_{2}$, and $3 \mathrm{mM}$ $\left.\mathrm{MnCl}_{2}\right)$, were prepared with purified water $(18.2 \mathrm{M} \Omega \times \mathrm{cm})$ and filtered through $0.22 \mu \mathrm{m}$-pore sized disks (Dassel, Germany) before use.

ConA from Canavalia ensiformis type IV, HRP from Amoracia rusticana type VI-A, TMB liquid substrate, calcium chloride anhydrous powder $99.99 \%$; manganese(II) chloride anhydrous beads $99.99 \%$; and the enzyme inhibitors (uracil $\geq 99.0 \%$, 2-thiouracil $\geq 99.0 \%$, 6-n-propyl-2-thiouracil, 6 - $n$ phenyl-2-thiouracil $\geq 95 \%$, 4-thiouracil 97\%, 5-carboxy-2thiouracil, 2-mercaptobenzimidazole $98 \%$, thiourea $\geq 99 \%$, imidazole $\geq 99 \%$, 1-methylimidazole $\geq 99 \%$, 2-methylimidazole 99\%, and 2-methylthio-2-imidazoline hydriodide 99\%) were purchased from Sigma-Aldrich (St. Louis, MO, USA). The Blu-ray disks (BDs 25 Gbyte) were from MediaRange $\mathrm{GmbH}$ (Bad Soden, Germany).

Experimental Procedure. ConA stock solution was prepared in activation buffer $(\mathrm{CAB})$ at $4 \mathrm{~g} / \mathrm{L}$ and kept at $-20{ }^{\circ} \mathrm{C}$ until use. Con A coating solution $(40 \mathrm{mg} / \mathrm{L}$ in $\mathrm{CB})$ was spotted $(25 \mathrm{~nL} / \mathrm{spot})$ on the $\mathrm{BDs}$ with the noncontact printing device $\mathrm{AD} 1500$ BioDot Inc. (Irvine, CA, USA) in a microarray format on the Blu-ray surface. To ensure reproducible volume delivery and microprinting quality, dispensing channel pressure, working temperature, and relative humidity were set at steady-state values. Furthermore, the robotic device tip was profusely washed with commercial BioTerge AS40 solution (from BioDot Inc.; Irvine, CA, USA) and purified water to ensure optimal printing to avoid crosscontamination. The spots were $250 \mu \mathrm{m}$ in diameter.

The coated BDs were incubated at $37{ }^{\circ} \mathrm{C}$ for $2 \mathrm{~h}$ to ensure the physical immobilization (passive adsorption) of the ConA on the surface of the Blu-ray disk. ${ }^{29}$ Then, the disk surface was rinsed with PBS-T and distilled water. After that, $1.0 \mathrm{~mL}$ of HRP solution $(20 \mathrm{mg} / \mathrm{L}$ in PBS-T) was dispensed onto the disk and homogeneously distributed using a transparent PC dummy surface. After 30 min incubation, the disk was washed as before. The protein-to-protein binding was characterized by contact angle measurements using the tensile drop method (Figure S1).

The reference activity of the enzyme was measured using a blank solution (1:4 solution $(\mathrm{v} / \mathrm{v})$ of dimethyl sulfoxide (DMSO)/PBS without target compound $(\mathrm{TgC})$ ). Finally, the enzymatic activity was measured using TMB as a substrate. The optical density of the generated colored precipitate was correlated to the enzymatic activity. To perform the inhibition assay, the TgCs were prepared in a $1: 4$ solution $(\mathrm{v} / \mathrm{v})$ of DMSO/PBS within a concentration range between 0.64 and $20 \mathrm{mM}$ (no influence of DMSO at $25 \%(\mathrm{v} / \mathrm{v}$ ) on HRP activity was detected). For that, $40 \mu \mathrm{L}$ of TgCs were dispensed on each array and allowed to react for $20 \mathrm{~min}$ at $37^{\circ} \mathrm{C}$. The disk was then washed with deionized water and dried by centrifugation. Finally, $1.0 \mathrm{~mL}$ of TMB solution was homogeneously distributed all over the disk surface using the dummy surface. The disk was incubated for 1-20 min at room temperature. Finally, the disk was rinsed with deionized water and dried by gentle shaking.

Disk Drive Imaging. The operational principle of microarray disk reading and image analysis has been previously reported based on the quantification of the different reflectivities shown between sensing objects (in this case, the TMB blue solid product generated on ConA/HRP recognition events) located on the disk surface, and the disk surface itself. ${ }^{30}$ A standard BD-player, which operated with a laser beam $\lambda=$ $405 \mathrm{~nm}$, was used as the detector (LG Electronics; Englewoods, NJ, USA). A photosensor (EE-SY125), which included a $\lambda=950 \mathrm{~nm}$ infrared LED (Omron, Scahumburg, IL, USA), was integrated into the device to trigger data acquisition. A photodiode converted back-reflected light into an analogy electrical signal that was collected and amplified by a custom-built data acquisition board. The analogy signal correlated to the optical density of the reaction product, that is, analyte concentration. The $\mathrm{BD}$ drive's spatial resolution and scanning speed were monitored by the Nero Disc Speed V4 software from Nero Inc. (Glendale, CA, USA). In order to control data acquisition (sampling rate, detector gain, etc.), custom software (BioDisc) was used, which allowed the image to be exported to a grey scale code to a compressed tiff or bitmap format for data analysis.

\section{ASSOCIATED CONTENT}

\section{Supporting Information}

The Supporting Information is available free of charge on the ACS Publications website at DOI: 10.1021/acsomega.8b03537.

\section{Detailed materials and methods (PDF)}

\section{AUTHOR INFORMATION}

\section{Corresponding Author}

*E-mail: amaquieira@qim.upv.es.

ORCID $\odot$

Ángel Maquieira: 0000-0003-4641-4957

\section{Author Contributions}

The manuscript was written through contributions of all authors. All authors have given approval to the final version of the manuscript.

\section{Notes}

The authors declare no competing financial interest.

\section{ACKNOWLEDGMENTS}

This work was supported by the Spanish Ministry of Economy and Competitiveness and the European Region Development Fund under award reference: CTQ2016-75749-R.

\section{REFERENCES}

(1) Hughes, J. P.; Rees, S.; Kalindjian, S.; Philpott, K. Principles of Early Drug Discovery. Br. J. Pharmacol. 2011, 162, 1239-1249.

(2) Roddy, T. P.; Horvath, C. R.; Stout, S. J.; Kenney, K. L.; Ho, P. I.; Zhang, J. H.; Vickers, C.; Kaushik, V.; Hubbard, B.; Wang, Y. K. Mass Spectrometric Techniques for Label-Free High-Throughput Screening in Drug Discovery. Anal Chem 2007, 79, 8207-8213.

(3) Smith, A. Sreening for Drugs Discovery: The Leading Question. Nature 2002, 418, 453. 
(4) Lombardino, J. G.; Lowe, J. A. The Role of the Medicinal Chemist in Drug Discovery - Then and Now. Nat. Rev. Drug Discovery 2004, 3, 853-862.

(5) Gangadharan, N. T.; Venkatachalam, A. B.; Sugathan, S. HighThroughput and In Silico Screening in Drug Discovery. Bioresources and Bioprocess in Biotechnology; Springer Singapore: Singapore, 2017; pp 247-273.

(6) Miller, O. J.; Harrak, A. E.; Mangeat, T.; Baret, J.-C.; Frenz, L.; Debs, B. E.; Mayot, E.; Samuels, M. L.; Rooney, E. K.; Dieu, P.; et al. High-Resolution Dose-Response Screening Using Droplet-Based Microfluidics. Proc. Natl. Acad. Sci. U.S.A. 2012, 109, 378-383.

(7) $\mathrm{Lu}, \mathrm{C} . ; \mathrm{Li}, \mathrm{A}$. P. Enzyme Inhibition in Drug Discovery and Development: The Good and the Bad; Wiley, 2010.

(8) Ekins, S.; Ring, B. J.; Grace, J.; McRobie-Belle, D. J.; Wrighton, S. A. Present and Future in Vitro Approaches for Drug Metabolism. J. Pharmacol. Toxicol. Methods 2000, 44, 313-324.

(9) Kenakin, T. P. Enzymes as Drug Targets. Pharmacology in Drug Discovery and Development; Elsevier, 2017; pp 131-156.

(10) Khnouf, R.; Olivero, D.; Jin, S.; Coleman, M. A.; Fan, Z. H. Cell-Free Expression of Soluble and Membrane Proteins in an Array Device for Drug Screening. Anal. Chem. 2010, 82, 7021-7026.

(11) Copeland, R. A.; Harpel, M. R.; Tummino, P. J. Targeting Enzyme Inhibitors in Drug Discovery. Expert Opin. Ther. Targets 2007, 11, 967-978.

(12) Supuran, C. T. Advances in Structure-Based Drug Discovery of Carbonic Anhydrase Inhibitors. Expert Opin. Drug Discovery 2017, 12, 61-88.

(13) Chae, M.-S.; Yoo, Y. K.; Kim, J.; Kim, T. G.; Hwang, K. S. Graphene-Based Enzyme-Modified Field-Effect Transistor Biosensor for Monitoring Drug Effects in Alzheimer's Disease Treatment. Sens. Actuators, B 2018, 272, 448-458.

(14) Kong, W.; Wu, D.; Hu, N.; Li, N.; Dai, C.; Chen, X.; Suo, Y.; Li, G.; Wu, Y. Robust Hybrid Enzyme Nanoreactor Mediated Plasmonic Sensing Strategy for Ultrasensitive Screening of AntiDiabetic Drug. Biosens. Bioelectron. 2018, 99, 653-659.

(15) Wang, X.; Zhang, Y.; Yang, Y.; Wu, X.; Fan, H.; Qiao, Y. Identification of Berberine as a Direct Thrombin Inhibitor from Traditional Chinese Medicine through Structural, Functional and Binding Studies. Sci. Rep. 2017, 7, 44040.

(16) Akins, N. S.; Nielson, T. C.; Le, H. V. Inhibition of Glycolysis and Glutaminolysis: An Emerging Drug Discovery Approach to Combat Cancer. Curr. Top. Med. Chem. 2018, 18, 494-504.

(17) Rath, C. M.; Benton, B. M.; de Vicente, J.; Drumm, J. E.; Geng, M.; Li, C.; Moreau, R. J.; Shen, X.; Skepper, C. K.; Steffek, M.; et al. Optimization of CoaD Inhibitors against Gram-Negative Organisms through Targeted Metabolomics. ACS Infect. Dis. 2018, 4, 391-402.

(18) Tan, E. V.; Lowe, C. R. Holographic Enzyme Inhibition Assays for Drug Discovery. Anal. Chem. 2009, 81, 7579-7589.

(19) Marsh-Armstrong, B.; Fajnzylber, J. M.; Korntner, S.; Plaman, B. A.; Bishop, A. C. The Allosteric Site on SHP2's Protein Tyrosine Phosphatase Domain Is Targetable with Druglike Small Molecules. ACS Omega 2018, 3, 15763-15770.

(20) Saleem, H. N.; Saeed, M.; Batool, F.; Mansoor, H. J.; Saleem, H. N. Inhibition of Dengue Virus Protease by Eugeniin, Isobiflorin, and Biflorin Isolated from the Flower Buds of Syzygium Aromaticum (Cloves). ACS Omega 2019, 4, 1525-1533.

(21) Lu, H.; Tonge, P. J. Inhibitors of FabI, an Enzyme Drug Target in the Bacterial Fatty Acid Biosynthesis Pathway. Acc. Chem. Res. 2008, 41, 11-20.

(22) Morais, S.; Tortajada-Genaro, L.; Maquieira, Á. Array-on-aDisk? How Blu-Ray Technology Can Be Applied to Molecular Diagnostics. Expert Rev. Mol. Diagn. 2014, 14, 773-775.

(23) Arnandis-Chover, T.; Morais, S.; González-Martínez, M. Á.; Puchades, R.; Maquieira, A. High Density Microarrays on Blu-Ray Discs for Massive Screening. Biosens. Bioelectron. 2014, 51, 109-114.

(24) Arrabito, G.; Pignataro, B. Inkjet Printing Methodologies for Drug Screening. Anal. Chem. 2010, 82, 3104-3107.

(25) Saleemuddin, M. Bioaffinity Based Immobilization of Enzymes. Adv. Biochem. Eng./Biotechnol. 1999, 64, 203-226.
(26) Pandey, B.; Tan, Y. H.; Fujikawa, K.; Demchenko, A. V.; Stine, K. J. Comparative Study of the Binding of Concanavalin a to SelfAssembled Monolayers Containing a Thiolated $\alpha$-Mannoside on Flat Gold and on Nanoporous Gold. J. Carbohydr. Chem. 2012, 31, 466503.

(27) Morais, S.; Puchades, R.; Maquieira, Á. Disc-Based Microarrays: Principles and Analytical Applications. Anal. Bioanal. Chem. 2016, 408, 4523-4534.

(28) Avella-Oliver, M.; Gimenez-Romero, D.; Morais, S.; GonzálezMartínez, M. Á.; Bueno, P. R.; Puchades, R.; Maquieira, Á. INSEL: An in Silico Method for Optimizing and Exploring Biorecognition Assays. Chem. Commun. 2013, 49, 10868-10870.

(29) Rusmini, F.; Zhong, Z.; Feijen, J. Protein Immobilization Strategies for Protein Biochips. Biomacromolecules 2007, 8, 17751789.

(30) Badran, A. A.; Morais, S.; Maquieira, Á. Simultaneous Determination of Four Food Allergens Using Compact Disc Immunoassaying Technology. Anal. Bioanal. Chem. 2017, 409, $2261-2268$ 